\title{
The Application of Flipped Classroom in English Grammar Teaching in Second High School
}

\author{
Xueyun Zang \\ School of Foreign Studies \\ Qilu Normal University \\ Jinan, Shandong, China 250013
}

\begin{abstract}
The Flipped Classroom is derived from Forest park high school. Its origin idea is to put the video, which is made by teaching timely and performing by PPT, on the Internet to help the students who need to make for the missed class. After that, more and more people pay attention to it. Flipped Classroom is applied in a wide range of education fields, such as primary school, middle school, high school and even adult education. While in China, Flipped Classroom is at the stage of exploring and studying, and just parts of schools start to explore and apply. Based on this status, it focuses on the application of Flipped Classroom to English grammar teaching in second high school, and the purpose is to create a better teaching method to put the Flipped Classroom in English grammar teaching in second high school. the paper gives summary and reflection to the research results, and the significance is to let teachers make full use of classroom time to improve the teaching efficiency and help students learn English grammar effectively after understanding and analyzing students' needs.
\end{abstract}

Keywords-Flipped Classroom; second High school English; English grammar teaching

\section{INTRODUCTION}

The Flipped Classroom is first used in America, and as more and more people pay attention to it, Flipped Classroom is applied to a wide range of education fields, such as, Forest park high school model, Khan academy model, Riverside model unified school district, Harvard University model and Stanford university model. Now that, Flipped Classroom in China is at the stage of exploring and studying. Some schools adopt the Flipped Classroom in their common class and try to apply it into traditional class properly. However, the application of Flipped Classroom in English grammar teaching in second high school is litter than other fields. The paper focuses on the application of Flipped Classroom in English grammar teaching in second high school, and the purpose is to create a new teaching method for teachers to make full use of class time to teach what students really need to learn. At the same time, my paper offers a feasible and relatively complete teaching system for second high school teachers to use. In addition, some different teaching methods will be used to cooperate with Flipped Classroom in my paper to let students have more interests and motivation to learn. According to my paper, teachers can have the opportunity to use a feasible and relatively complete teaching system, which can transform students from passive learners to active learners, in their traditional class. By learning this theory teachers can make full use of classroom time to leadin and teach lessons after understanding, testing and analyzing students' needs before class. It not only supplies teachers a feasible and relatively complete teaching system to teach English grammar in second high school, but also provides students a wonderful chance to decide when and how to learn by themselves. As a result, more and more English teachers and students can be benefit from it, and more and more attractive and interesting classes will be produced. In this way, both teacher and student can learn more from it.

\section{ANALYSIS}

This paper focuses on second high school English grammar teaching and learning based on Flipped Classroom theory. Using a new way to develop students' study, the first purpose is to help students who are busy with activities. It can provide flexed available time for them to study before or after class. The second purpose is to help students who will come across difficulties when they study. It provides a good way for these students to study in their own study speed and their own way. The students can make notes and bring the problem which they do not deal with to classroom. The third purpose is to add interactions between teacher and students. Then students can show their problems and clarify where they really do not know in class. The fourth purpose is to let teacher know more about their students. It can provide more time for teacher to build relationships with their students. The five purposes are to realize auto-study. It can provide a good opportunity to realize hierarchical teaching. The last purpose is to change classroom management. It can let students who are naughty lose audience and realize their task of learning. In this part, teacher can teach in orders according to the materials collected before class and problems appeared at class. This is a good way for teachers to design a suitable teaching plan for students, make full use of class time and teach students what they really need to learn.

When teachers use the Flipped Classroom theory, they need to analysis whether the new knowledge really need to be presented in this way. That's to say, although Flipped classroom theory is effective in some aspects, it is not fit for all English classes. One reason is that once teachers choose 
apply the Flipped Classroom theory, they need to prepare many materials, such as power point or video which they transcribed before class. Another reason is that the Flipped Classroom need to be analyzed whether they can guide practice, how to combine the procedural knowledge and specific practical knowledge, and how to creatively solve the specific problems by using the theory. In this part, it needs to cost time and energy of teachers, and it sometimes needs students' time allowable. So teachers need to think carefully before use the Flipped Classroom theory. The steps are as follows.

\section{A. Data Analysis}

The analysis of data is a process of inspecting, cleaning, transforming, and modeling data with the goal of discovering useful information, suggesting conclusions, and supporting decision-making. Data analysis has multiple facets and approaches, encompassing diverse techniques under a variety of names. And using the $\mathrm{T}$ test to do data analysis is more believable.

The test tested the significance of two samples, based on two samples' mean, testing whether the corresponding difference between the average is a real difference. After the survey, the average in one class is 85.37and the other is 85.39 , so the $\mathrm{P}$ value $<0.05$ and it indicates that the differences between the two sample is not a coincidence, it means that data is with statistical significance, and is also the overall significant differences. When the data is statistical, the result of the experiment is more believable and persuasive. It means that this paper can provide a data which can be used and analyze.

\section{B. The Story Teaching Method}

When moving to this part, teacher should pay more attention to students' emotion carefully. Because in this part, teacher's action from teaching to promoting and guiding. It not means the teacher's effect is lower but high. Teacher need to have a detailed analysis of each teaching link to provide the corresponding support, promote students to study better and truly become the study master. First step, teacher can provide an open relatively challenging topic. Second step, teacher can divide students into several groups, and students can choose their partners. Third step, every group can present their production after finishing their tusk. Forth step, teacher and students can elect champion by a vote. The last step, teacher can give a physical reward. All steps in this part not only perform effectively but also in orders. As a result, teacher can apply this method in different parts of English teaching lessons, especially in leading in new topics or new English grammar points.

In reality, the storied theory is based on the Flipped Classroom theory. Before class, teacher not only needs to provide some learning materials for students read and learn, but also needs to design a classroom situation which is fun, thinking, challenging, competitive and can stimulate learners interest. When in class, teachers need to present and make tasks according to different groups. Students need to explore and try to solve problems. Then they need to apply, present and communicate by themselves. At last,all these presentations need to be rewarded in different ways under different topics.

\section{Question and Answer Method}

Questioning is the effective way to inspire students to active thinking, so designing issues must maintain logical and systematic, neither aggressive nor conservative. When students answer the question they can do active thinking and have interests in learning new things. And the difficulty of questions should be acceptable; most students are able to answer. If some students do not give right answer, teacher needs to encourage them and give positive elevation. In fact, no matter the students' answer is right or wrong, the most important thing teacher should pay attention to is whether they know the really thing that teacher wants to teach them. The key of this part is to raise students' learning desires and interests, lead them learn more they do not know before.

\section{Discussion Method}

Discussion is the method that students under teacher's instruction to solve a problem by carrying on the discussion and discerning the authenticity to obtain the knowledge. The advantages of this method are to increase the initiative and the enthusiasm of students, to cultivate students' independent thinking ability, oral expression ability, and to promote the students to use the knowledge flexibly. Before the discussion, teacher should do some researches and interviews with some students and then design up appropriate questions and list up some useful information already. When class is beginning, teacher should perform naturally and give some time for students to prepare for their presentation. The discussion needs overall grasp and details grasp, students can learn concentrating on the main points through overall grasp and learn specific knowledge though details grasp. Topic design is the core of discussion. The key of the auto-study is to transform the traditional teaching process into the task driven and problem oriented process, which is the basement of the Flipped Classroom theory. And the discussion topic is designed for the aim of learning. All these parts not only develop students' auto-study skills but also exercises their language communication skills.

\section{E. Role Play and Dialog Method}

Role-play, or acting, is an effective teaching skill which can make the students concentrate on language learning, focus on training the ability of listening and speaking. This part needs students' well understanding of content of the text.

Listen to the dialog and answer questions, which can help student actively take part in activities and pay more attention to new knowledge. In the end, they can use their own way to express their ideas about the dialog.

Role-play and dialog are both good ways for students to know what language is and how to use it. Firstly, teachers tell them how to do in this part and students begin to do autonomous exploration. After observation, teachers give proper guide and let students present their show. In the end of their presentation, teacher can organize students to communicate and evaluate with each other. The purpose of 
this part is to avoid superficial and formal learning. Through this way, student not only learn English grammar but also learn how important to speak English meaningfully. The most important thing is that they are putting language into real life in learning process.

\section{F. Reflection and Consolidation}

Reflection and consolidation plays a very important role in study. When students learn how to reflect themselves and how to develop their study, they have already developed a good study habit. One lesson later, teachers need to organize students to reflect their study. Reflect their error and perfect performance to consolidate their knowledge and summary experience. Teacher can let students keep log to reflect and put out on communication plat. It not only a accumulation for students' learning but also a good way for teachers to form a accurate evaluation after class. It can also provide a good way for students to communicate experience and lesson, consequently developing studies with each other. Of course teachers must know reflection and consolidation. If teachers want to know how to high up students' English learning level, teachers must know which way is the most suitable way for them, and what they really need. Through research method, questionnaire method, data collection method, interview method and data analysis method, teacher can have some true and useful information, which is the very material for them to think about, correct, and prepare their lessons. These materials just like the collection of visual effect of course video resources, the analysis on whether the video can stimulate the students interest, the data collection on whether the video length is appropriate and the analysis of interaction of video content. In addition, teacher can reflect their classroom time with students. These aspects just like the times teacher's teaching, the appropriation of teaching content, the interaction between teachers and students, the frequency of students interaction, whether there are advanced thinking. Then the class time will make for student rather than teacher, the class center will change from teacher to student. That's the Flipped Classroom's real meaning.

\section{G. Testing and Modification}

Apply the teaching method provided above into tree classrooms in second high school in three different places. Based on the teaching environment, this paper's analysis focuses on the two classes in Shiyan second high school in city. The two classes are grade 2 class 3 which is the experimental class and grade 2 class 6 which is the control class. The process is as follows:

Before the grammar teaching, the teacher put the rules, special usage, and idiomatic expressions involved in the grammar into teaching video, and present all the grammar rules in the video with vivid pictures and detailed and accurate language. Then distribute these video to class 3 and tell them to study at home using the summer vacation with the right of choosing study time and manner as they like. While students in class 6 need to read books by themselves and learn grammar. After their holidays, teacher use situational teaching method to let the students use the grammar in the creation of situations. As a result, class 3 complete very smoothly, while class 6 get into trouble in the choice of words, low the degree of completing exercises and spend more time when do second grammar explanation. After one week, the problem solving quality of class 3 is $10 \%$ higher than class 6 . As a result, this paper have summarized the advantages of the Flipped Classroom theory. The Flipped Classroom transforms duty from the teacher to students. Using video teaching, students can choose study time, place, manner according to their own situation. Students can watch video explanation outside the classroom or at home, absolutely in a relaxed atmosphere instead of serious study atmosphere in classroom. The rhythm of watching the video is completely in students' hands. When they understand they can fast forward, if not back again to watch or Stop to think carefully and take notes. The flexibility of learning is enhanced, interest in learning is very strong. The Flipped Classroom strengthens the interaction in the classroom, increases mutual cooperation between teachers and students, students and students. And when students have more time to exchange, students will develop collaborative group, help each other and learn from each other.

\section{RESULT AND DISCUSSION}

\section{A. Providing a Teaching System}

The teaching system provided in the end must contains the following aspects: the suitability of content, teachers and students emotional exchange in class, effectively formative assessment. For the aspect of suitability of content, majority of teachers and students accept easily as computer with its large amount of information, fast delivery and superiority, but in the process of aiding teaching knowledge through multimedia, information must be appropriate and the content must be representative. Only in this way can we truly achieve the integration of sense, develop the learning ability of the students. For second aspect, multimedia aided teaching making the design of in English class more challenging. Natural language between people is the most affinity and flexible language, so the interaction between teachers and students should be the most effective way of teaching and learning. In the teaching process, teachers should enlighten students' emotional activities; enable students to actively participate in each link of classroom teaching. Only in this way, teachers can control well the classroom. For the third part, the Flipped Classroom can achieve teaching by learning. Class becomes students' display space instead of teacher's stage and the comprehensive quality including knowledge, emotion, strategy and objectives are improved in class. Accordingly, teachers should pay attention to the development of each student Building up manual, archives which record and positively evaluate students' harvest. Then puts forward some suggestions, guide the students to learn how to learn and learn how to be good at learning. Only the passive learning become the active guidance and active learning, can students truly become the main manager of the English classroom, creating the atmosphere of English learning. The students' English expression ability and comprehensive quality can be improved, making English 
teaching return to the truth, realizing the comprehension and communicating in context.

\section{B. Teaching Practice and Application}

The Flipped Classroom in second high school English grammar teaching needs several times practice and modify, then be applied into real teaching class. When teachers apply the Flipped Classroom in English grammar teaching, they should know that the Flipped Classroom is not just the overturn of the traditional class, but is the fundamental changes in the structure of the curriculum teaching from the perspective of respecting people and the development of people. This change not only requires the teachers having new requirements, but also requires students' ability in learning new knowledge by themselves. Therefore, repositioning the roles of teachers and students, fine reconstruction of classroom teaching video and classroom dialogue is an efficient approach to realize the flipped classroom.

Whether it is flipped classroom or traditional classroom, all are the process of teaching interaction around the question situation. This paper is insufficient in English grammar teaching in second high school based on the Flipped Classroom theory in some extent, so it needs continuing application and practice in the future, forming specific data to verify the flipped classroom.

\section{RERERENCES}

[1] Chen Li. The Application of Flipped classroom in English During the Stage From the Primary to Junior Middle School. Weekly Journal for Examination[J]. 2014(13):105

[2] Li Chao. The Application of Flipped Classroom in English Teaching in Junior Middle School. Weekly Journal for Examination[J]. 2014(52):34

[3] Lu Qiang. Critical Thinking of Flipped Classroom: Proof and Reflection[J]. Curriculum and Teaching [J].2013(8)91-97

[4] Huang Weiwei. Flipped Leaning: A New Model for Classroom Teaching Reformation. Electrified Education Research[J]. 2013:65 